\title{
Insights into electrolytic stabilization with weak polarization as treatment for archaeological copper objects
}

\author{
Annemie Adriaens • Mark Dowsett • Karen Leyssens • \\ Bjorn Van Gasse
}

Received: 4 July 2006 /Revised: 4 September 2006 / Accepted: 5 September 2006 / Published online: 18 October 2006

(C) Springer-Verlag 2006

\begin{abstract}
Immersion of corroded copper artefacts in dilute sodium sesquicarbonate solution is a well-recognized stabilization technique - especially in the conservation of objects recovered from marine environments and therefore saturated with chlorides. Here we describe three linked experiments performed to investigate a variation on this treatment, involving the application of a low potential to the artefact in order to drive the chloride extraction process. This includes a new spectroelectrochemical approach which allows 2-D pseudorandom X-ray reflection diffraction patterns to be obtained without interrupting the reaction in solution. Experiments were carried out on synthetically produced chloride layers on copper (nantokite and atacamite). We show that a thick chloride layer is, in general, replaced by a thin cuprite layer through a mechanism which involves detachment of the chloride crystallites from the surface prior to dissolution.
\end{abstract}

Keywords Cultural heritage - Conservation - Stabilization . Cupreous objects · Spectroelectrochemistry $\cdot$ SR-XRD .

Chronoamperometry
A. Adriaens $(\bowtie) \cdot K$. Leyssens $\cdot$ B. Van Gasse

Department of Analytical Chemistry, Ghent University, 9000 Ghent, Belgium

e-mail: annemie.adriaens@ugent.be

\section{Dowsett}

Department of Physics, University of Warwick, Coventry CV4 8UW, UK

\section{Introduction}

Stabilization treatments are used in conservation strategies in the field of cultural heritage and are performed to preserve the object and sometimes also part of the corrosion layer. In particular, chloride-containing corrosion products require attention when dealing with cupreous objects, as they are very unstable mineral compounds that can lead to the complete destruction of the object. In the presence of moisture and oxygen, copper chlorides are hydrolyzed to form hydrochloric acid and basic cupric chloride. The hydrochloric acid in turn attacks the uncorroded metal to form more cuprous chloride [1].

Any conservation of chloride-contaminated cupreous objects requires that the chemical action of the chlorides be inhibited, either by removing them or by converting them to harmless cuprous oxide. The use of sesquicarbonate solutions has become a standard element in the stabilization of corroded cupreous objects recovered from marine environments. When bronzes or other alloys of copper are placed in a $1 \mathrm{wt} \%$ solution of sodium sesquicarbonate $\left(\mathrm{NaHCO}_{3} \cdot \mathrm{Na}_{2} \mathrm{CO}_{3}\right)$, it is reported that the hydroxyl ions of the alkaline solution react chemically with the insoluble cuprous chlorides to form cuprous oxide and to neutralize any hydrochloric acid by-product formed by hydrolysis to produce soluble sodium chlorides [1-3].

The chloride concentration in the solution builds up over time and so, if the solution is repeatedly changed, the chlorides are removed. The object is then rinsed in several deionized water baths until the $\mathrm{pH}$ of the last bath is neutral. Initially, the baths are changed weekly; as the duration of treatment progresses, the interval between bath changes is extended. Monitoring the chloride level in the solution enables the conservator to determine how often the 
solution should be changed. The cleaning process is slow and may require months and, in some cases, even years [4-8].

In their work, Païn et al. and later also both Lamy and Bertholon investigated a variation on the above-mentioned treatment which was employed to increase the extraction rate of chlorides, thereby reducing the object treatment time [9-11]. The essence of the method involves setting up an electrochemical cell with the artefact as the cathode in a sodium sesquicarbonate solution, and applying a small potential to the artefact. The method is referred to as electrolytic treatment with weak polarization or as electrolysis under low overvoltage. The authors showed that the extraction of chlorides increases significantly, leading to a reduction of the treatment time of a factor of three. They did not observe any change of the surface appearance of the objects.

However, this is not always the case: Ehanti, for instance, reported on the stabilization of sixteenth century cupreous cauldrons using electrolytic polarization in a $1 \mathrm{wt} \%$ sodium sesquicarbonate solution [12]. During the treatment, various changes in the appearance of the surface were observed in the form of white and blue-violet patches on the patina.

In this work, the effect of the treatment on the surface is examined in detail by monitoring the chemical surface composition using electron microscopy and in situ timeresolved SR-XRD.

\section{Experimental}

The study consisted of three experiments which, taken together, provided information on the progress and effect of the treatment.

In each experiment a copper coupon, artificially corroded with either nantokite or atacamite, was immersed into a $1 \mathrm{wt} \%$ sodium sesquicarbonate solution, which was prepared by dissolving $11.89 \mathrm{~g} \mathrm{Na}_{2} \mathrm{CO}_{3} \cdot \mathrm{NaHCO}_{3} \cdot 2 \mathrm{H}_{2} \mathrm{O}$ (Sigma, St. Louis, MO, USA) in $1 \mathrm{~L}$ deionized water (pH10). A potential of $-0.10 \mathrm{~V}$ vs SHE was applied to the sample using a handheld potentiostat (Palm Instruments BV, Houten, The Netherlands). All three experiments used chronoamperometry (i.e., measurement of the current as a function of time) to monitor the progress of the treatment. Once the current drops to zero, it is assumed that the reaction has ceased.

In the first experiment, the solution was stirred using a magnetic flee and stirrer. At regular time intervals, the potential was switched off and the chloride concentration in the solution was measured using an ion-selective electrode sensitive to chloride ions (ISE/HS25Cl, Radiometer Analytical, Villeurbanne Cedex, France). Images of the surface were also taken at that moment using an optical microscope [Nikon (Tokyo, Japan) SMZ 800 microscope with a P-IBSS Single Port Beamsplitter] together with a digital camera [Canon (Tokyo, Japan) Powershot A75)]. In this way, the surface could be analyzed with magnifications of up to 80 times.

In the second experiment, cross-sections of the samples were examined using scanning electron microscopy with energy dispersive X-ray detection (SEM-EDS) in order to obtain information about the morphological features and chemical composition of the corrosion layer before and after treatment. The SEM-EDS analyses were performed on an FEI Quanta 200F (Philips, Eindhoven, The Netherlands) at $12.5 \mathrm{kV}$ acceleration voltage. The samples have been coated with a thin layer of gold to avoid charging effects. EDS analyses were performed by an EDAX Genesis 4000 energy-dispersive X-ray spectrometer (EDAX, Mahwah, NJ, USA). ZAF corrections have been applied when quantifying the elemental composition.

The third experiment used synchrotron radiation X-ray diffraction (SR-XRD) simultaneously with the chronoamperometry. Two-dimensional diffraction images of the surface were taken every 2.5 minutes. These provide information about the chemical composition of the surface. The difference from the first experiment is that the treatment is not interrupted; i.e., the SR-XRD data are taken while the potential is applied to the sample.

Sample preparation

Circular copper coupons, $12 \mathrm{~mm}$ in diameter (Advent, Oxford, UK, purity 99.9\%), were made into electrodes that fit the electrochemical cell described below (see working electrode assembly in Fig. 1). The coupons were connected to a brass rod by means of conducting glue, and were encapsulated in acrylic so that only one surface was exposed to the electrolyte. A brass stud in a tapped hole in the rod attached the electrode to the cell, and an O-ring sealed against the acrylic to exclude electrolyte from the electrical contact thus formed.

The electrodes were ground on 1200 grit $\mathrm{SiC}$ paper to obtain a fresh surface. Further smoothing of the surface was carried out using a polishing cloth covered with alumina powder of $1 \mu \mathrm{m}$ particle size. The adherent $\mathrm{Al}_{2} \mathrm{O}_{3}$ particles on the surface were removed by immersing the samples in an ultrasonic bath for 15 minutes and rinsing them thoroughly with deionized water.

The samples were corroded artificially using various corrosion protocols to obtain different chloride-containing corrosion products, including nantokite $(\mathrm{CuCl})$ and atacamite $\left(\mathrm{Cu}_{2}(\mathrm{OH})_{3} \mathrm{Cl}\right)$. Copper covered with nantokite $(\mathrm{CuCl})$ was obtained by immersing pure copper coupons for one hour in a saturated $\mathrm{CuCl}_{2} \cdot 2 \mathrm{H}_{2} \mathrm{O}$ solution (VWR Interna- 
tional, West Chester, PA, USA). After rinsing with deionized water they were exposed to the air overnight [11]. For the atacamite corrosion, a solution of $15.07 \mathrm{~g}$ of $\left(\mathrm{NH}_{4}\right)_{2} \mathrm{CO}_{3} \cdot \mathrm{NH}_{3}$ (Fluka, Deisenhofen, Germany) and $10.02 \mathrm{~g}$ of $\mathrm{NH}_{4} \mathrm{Cl}$ (Aldrich, Steinheim, Germany) in $100 \mathrm{~mL}$ of deionized water was prepared. The copper samples were wetted twice a day with this solution. This procedure was repeated over a period of five days. Between each application, the samples were left to dry in the air. The samples were left in air for a further five days without any treatment [11].

\section{Electrochemical cell}

The electrochemical cell ("eCell") used for the treatment was a specialized electrochemical cell compatible with synchrotron radiation XRD, and other X-ray based methods, e.g., EXAFS and ODXAS were used. The cell was made from PCTFE for good chemical resistance and reasonable mechanical stability. It was basically a cylinder $60 \mathrm{~mm}$ in diameter and $100 \mathrm{~mm}$ high containing a piston which was driven along the bore by a stepper motor through a dynamic seal. The working electrode, whose surface forms the sample for X-ray analysis, was mounted on the piston. It could be moved precisely to translate the reacting surface from an "electrochemical" position, in proximity to a reference electrode, through an annular platinum counter electrode to a "diffraction" position close to a flexible $8 \mu \mathrm{m}$-thick Kapton window. In the latter position, the path length for X-rays in the electrolyte was a fraction of a millimeter to reduce scattering and X-ray absorption. In order to get permanent potential control on the electrode surface, a rigid polyethylene tetraphthalate inner window with a rectangular or elliptical hole in the middle was positioned just inside the Kapton, limiting the electrolyte thickness in a reproducible manner to 100 $175 \mu \mathrm{m}$, depending on its thickness. In this way, the cell could be used down to X-ray energies below $8 \mathrm{keV}$. The two windows were tightly fastened onto the cell body by an O-ring. The cell was equipped with a silver/silver chloride reference electrode and a platinum counter electrode. Figure 1 shows a schematic diagram of the cell. The prototype of the cell used is described in more detail elsewhere [13]. The system also had a webcam, which allowed video or stills of the operation of the eCell to be observed and captured.

\section{SR-XRD analyses}

Experiments were performed at XMaS (Station BM28, European Synchrotron Radiation Facility, Grenoble). At this station, a beam with a wavelength of $1.5498 \AA$ and with dimensions of $1 \mathrm{~mm} \times 200 \mu \mathrm{m}$ was used. A 2D Mar CCD 165 detector (Mar USA Inc., Evanston, IL, USA) was

Fig. 1 Schematic of the electrochemical cell used in this work

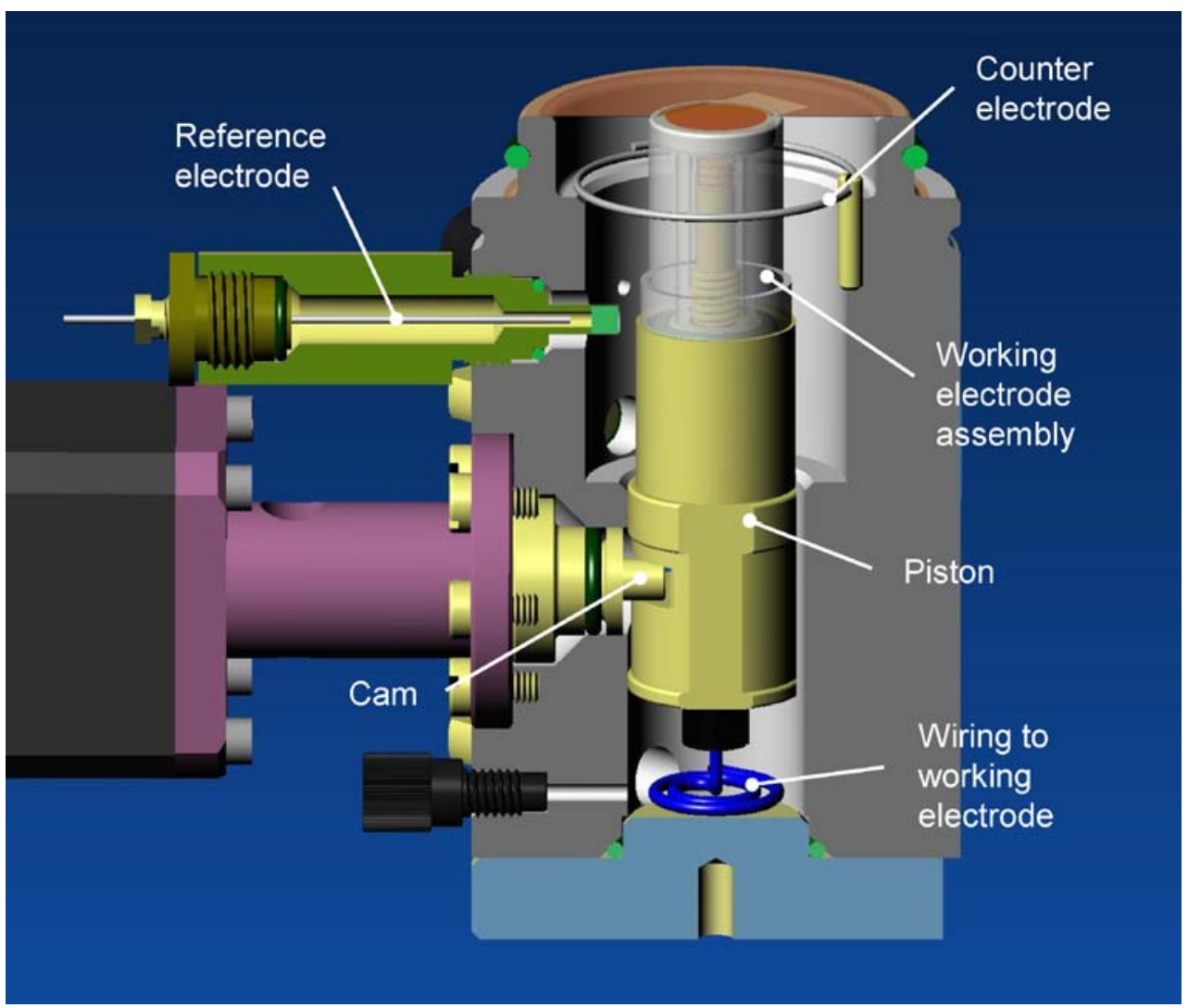


used to record the diffraction patterns. This is an important feature of these experiments, because the samples are not necessarily totally random in orientation, and the surface reactions can result in both changes in coverage and changes in orientation. A 1-D in-plane detector can exhibit changes in relative intensity between peaks from the same chemical species, which can lead to erroneous assumptions about concentration if only one peak is monitored. Changes in orientation, however, lead to easily discernable evolution of the fine structure in the diffraction rings in the 2-D case, and integration of the rings to produce a spectrum will average out such effects. X-rays were incident at $10^{\circ}$ to the sample surface (we show elsewhere [9] that this produces a reasonably optimal combination of surface specificity and a short path length in the fluid). The angle of the camera to the beam was $45^{\circ}$ in order to be able to acquire the signals $2 \Theta$ values of $15^{\circ}$ and $75^{\circ}$. Under these conditions, the diffraction centre is outside the field of view of the camera, and the camera plane intersects the diffraction cones at an angle to produce elliptical "rings". The images were processed using a new software program, esaProject, which was developed for this purpose.

The sample was placed in the electrochemical position for $150 \mathrm{~s}$, after which it was moved up to the diffraction position, where a diffraction pattern was acquired over $10 \mathrm{~s}$. The sample was then moved back to the electrochemical position.

\section{Results and discussion}

Figure 2 shows the measured current density and the chloride concentration in solution as a function of time for a sample corroded with nantokite. The current shows a rapid decrease over the first ten minutes, and has reduced by $99 \%$ after 20 minutes. The treatment ends at this point, as confirmed by the fact that the chloride concentration remains stable as of the third measurement (15 minutes). After 60 minutes of treatment, the sample is immersed in a fresh sodium sesquicarbonate solution, at which point the chloride concentration falls below the detection limit and stays there. The optical images, taken over the same interval as the chloride concentration measurements, are shown in Fig. 3 and confirm the above data: within ten minutes the gray-green colour of nantokite is converted into the brown-orange color typical of cuprite.

Secondary electron images of a cross-section of the sample before and after treatment (Fig. 4) show a clear reduction in the thickness of the corrosion layer. Before the treatment, the corrosion layer shows a more or less uniform thickness of $25 \mu \mathrm{m}$, while the thickness varies from 2 to $10 \mu \mathrm{m}$ after the treatment. EDS analyses reveal that only a small amount of chloride is left after treatment (Fig. 5).

Figure 6 shows that the atacamite sample has reached maximum chloride extraction after 25 minutes. The current density, however, indicates that the reaction has not finished. This is confirmed by the set of optical images taken over the same time intervals (Fig. 7), which demonstrate that at 25 minutes after the start of the treatment atacamite is still present on the sample. At 60 minutes after the start of the treatment, the sample is immersed into a fresh sesquicarbonate solution. At this point it has become clear that the atacamite is attached very loosely to the metal, as part of it actually falls off. The chloride concentration in the new solution is below the detection limit and stays there in spite of the fact that
Fig. 2 Current density and chloride concentration as a function of time for the copper/ nantokite sample

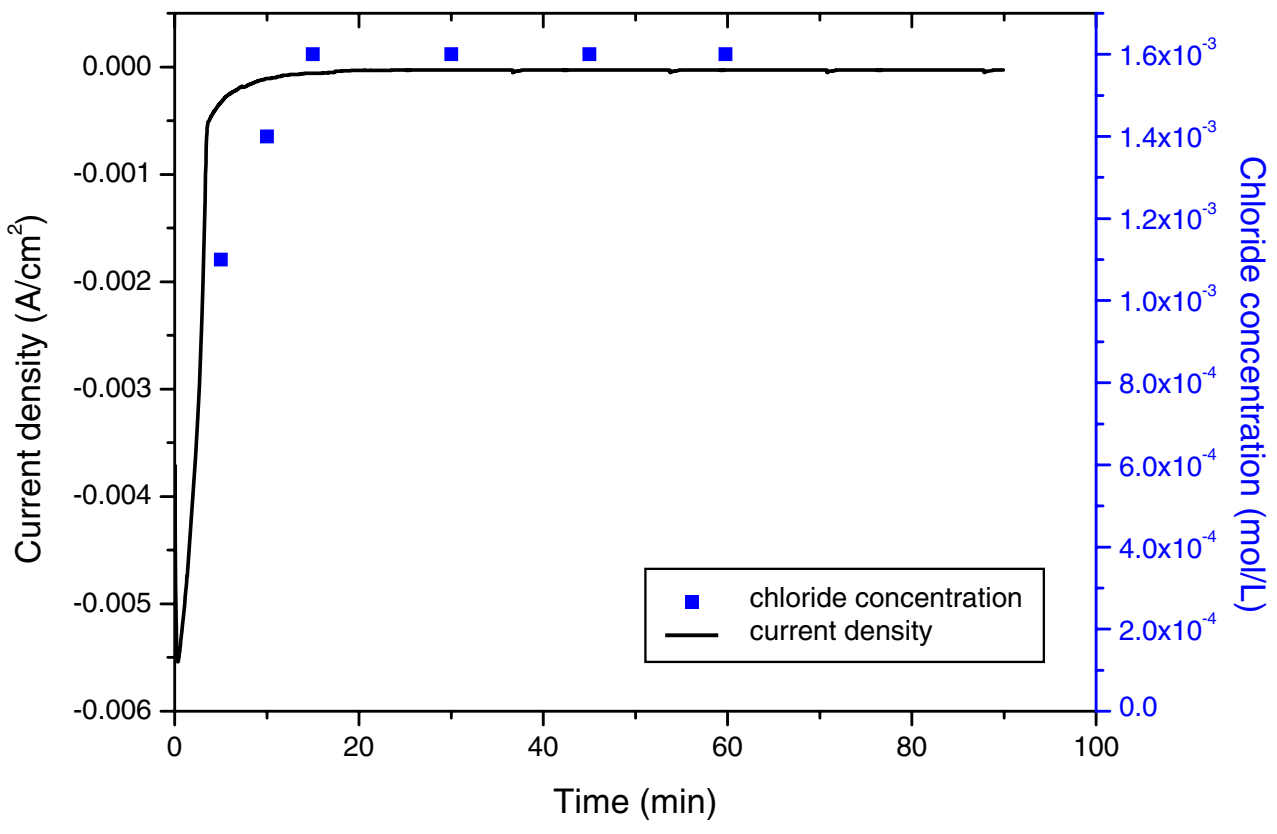


Fig. 3a-f Set of optical images of the copper/nantokite sample taken after 0 minutes (a), 5 minutes (b), 10 minutes (c), 15 minutes (d), 30 minutes (e) and 90 minutes (f) of treatment
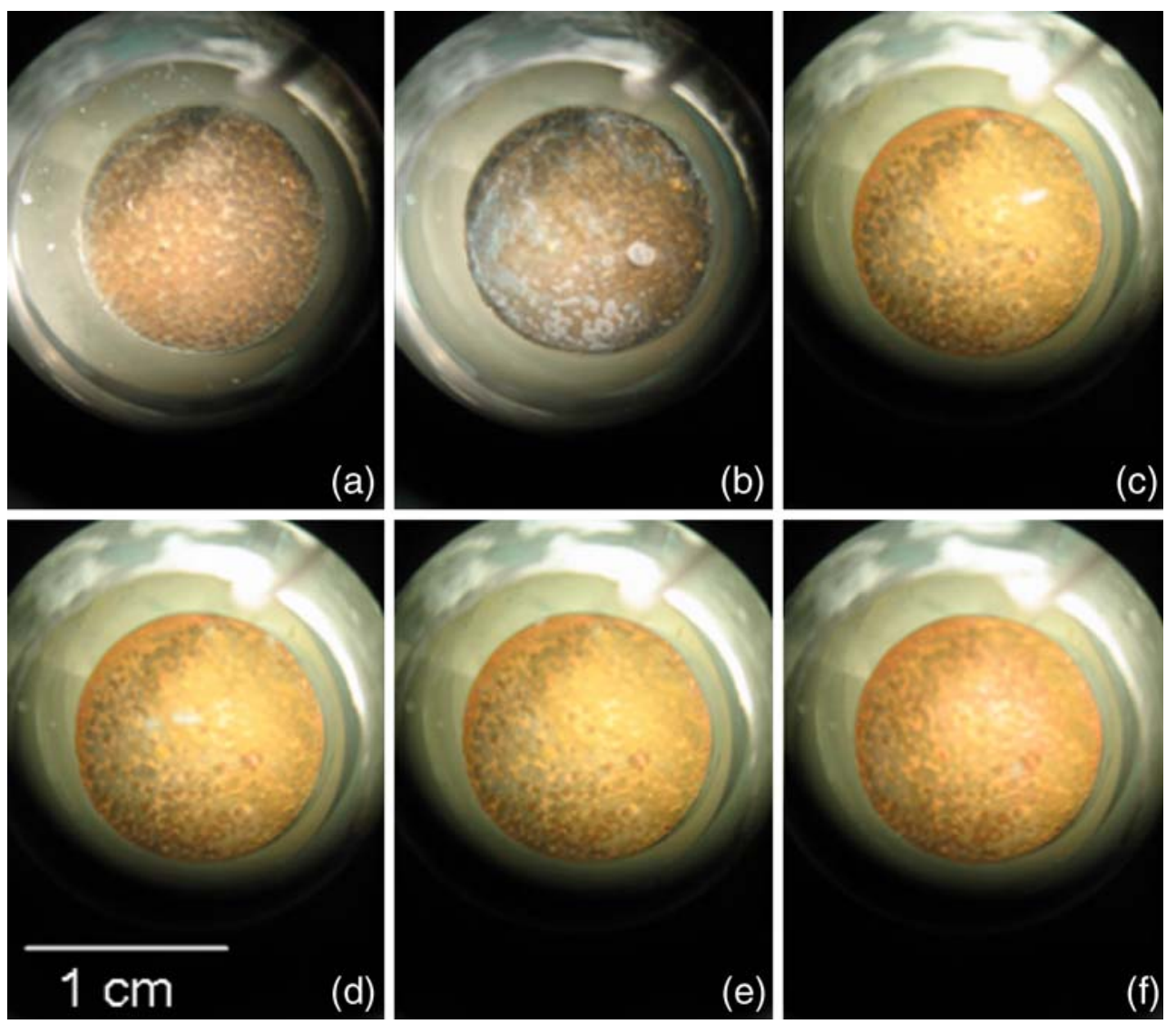

the amount of atacamite on the sample decreases further as a function of time.

Figure 8 shows a small set of images from the SR-XRD image sequence for the atacamite sample. The upper row in each case shows the data as collected, whilst the lower shows the reprojected data obtained from our software esaProject. esaProject re-maps the images into $2 \Theta-\gamma$ space (or, alternatively, $d-\gamma$ space), where $2 \Theta$ is the total scattering angle, $\gamma$ is the out-of-plane scattering angle, and $d$ in this case is the plane spacing divided by the order of diffraction. In this map, the elliptical rings are straight bars and all or part of the image is easy to integrate to form a spectrum. esaProject keeps track of the number of pixels from the original image accumulated into any row of the reprojected map (effectively the lengths of the elliptical arcs comprising the rings), so that the peaks in the spectrum are properly normalized against the active detector area in that ring.

The images show the changes in the electrode diffraction pattern as various reactions were driven. Elapsed time from
Fig. 4a, b Secondary electron images of the cross-section of the copper/nantokite sample before (a) and after (b) 180 minutes of treatment. The gold peak in spectrum (a) is due to the gold coating used to avoid charging effects
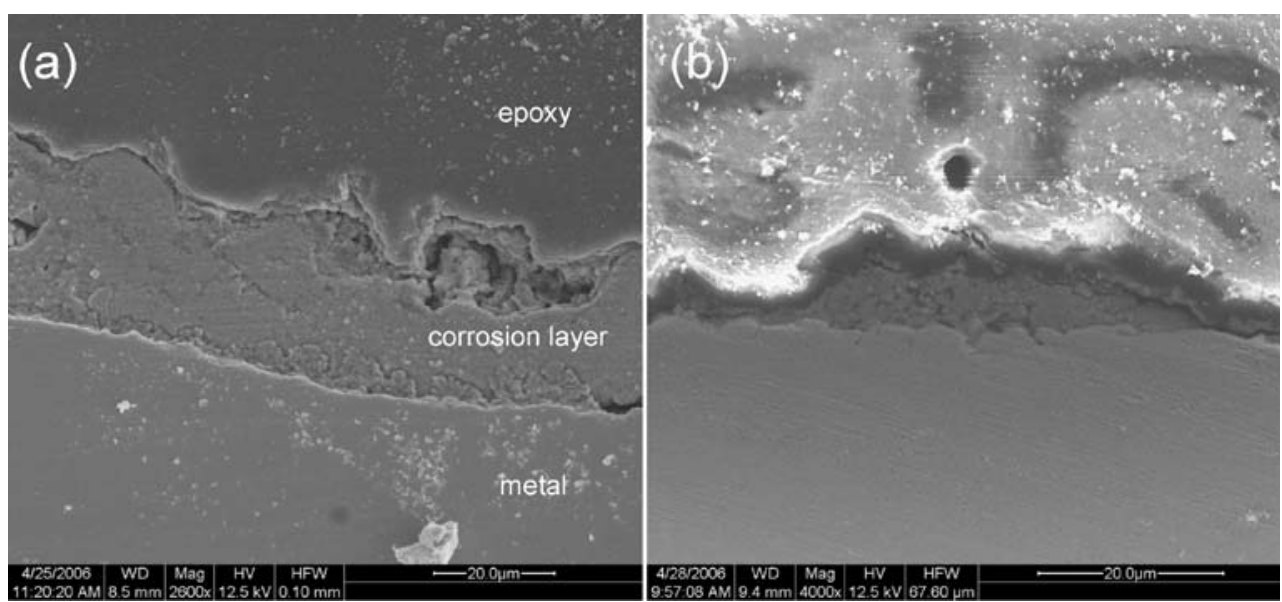
Fig. 5a, b SEM-EDS spectra of the nantokite corrosion layer before (a) and after (b) 180 minutes of treatment. The $\mathrm{Au}$ peaks result from the gold coating

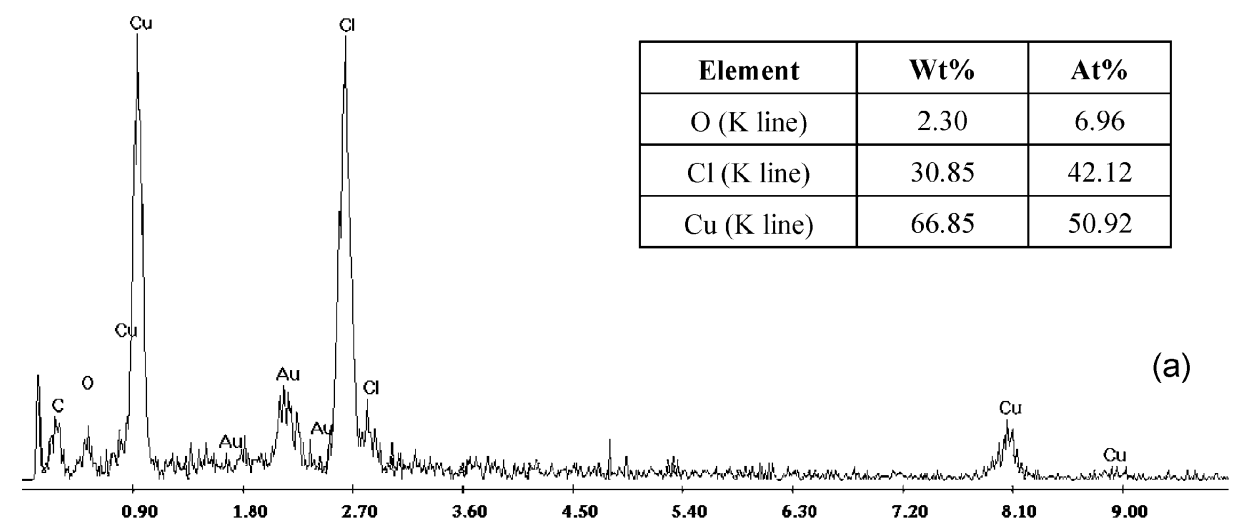

$\frac{?}{0}$

\begin{tabular}{|c|c|c|}
\hline Element & $\mathbf{W t} \%$ & $\mathbf{A t} \%$ \\
\hline $\mathrm{O}(\mathrm{K}$ line $)$ & 9.90 & 30.28 \\
\hline $\mathrm{Cl}(\mathrm{K}$ line $)$ & 0.45 & 0.75 \\
\hline $\mathrm{Cu}(\mathrm{K}$ line $)$ & 89.56 & 68.97 \\
\hline
\end{tabular}

(b)

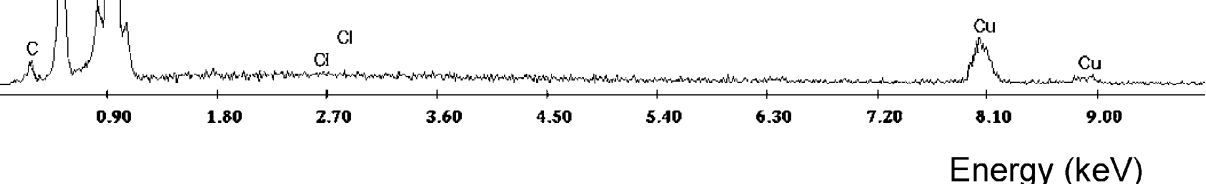

Fig. 6 Current density and chloride concentration as a function of time for the copper/ atacamite sample

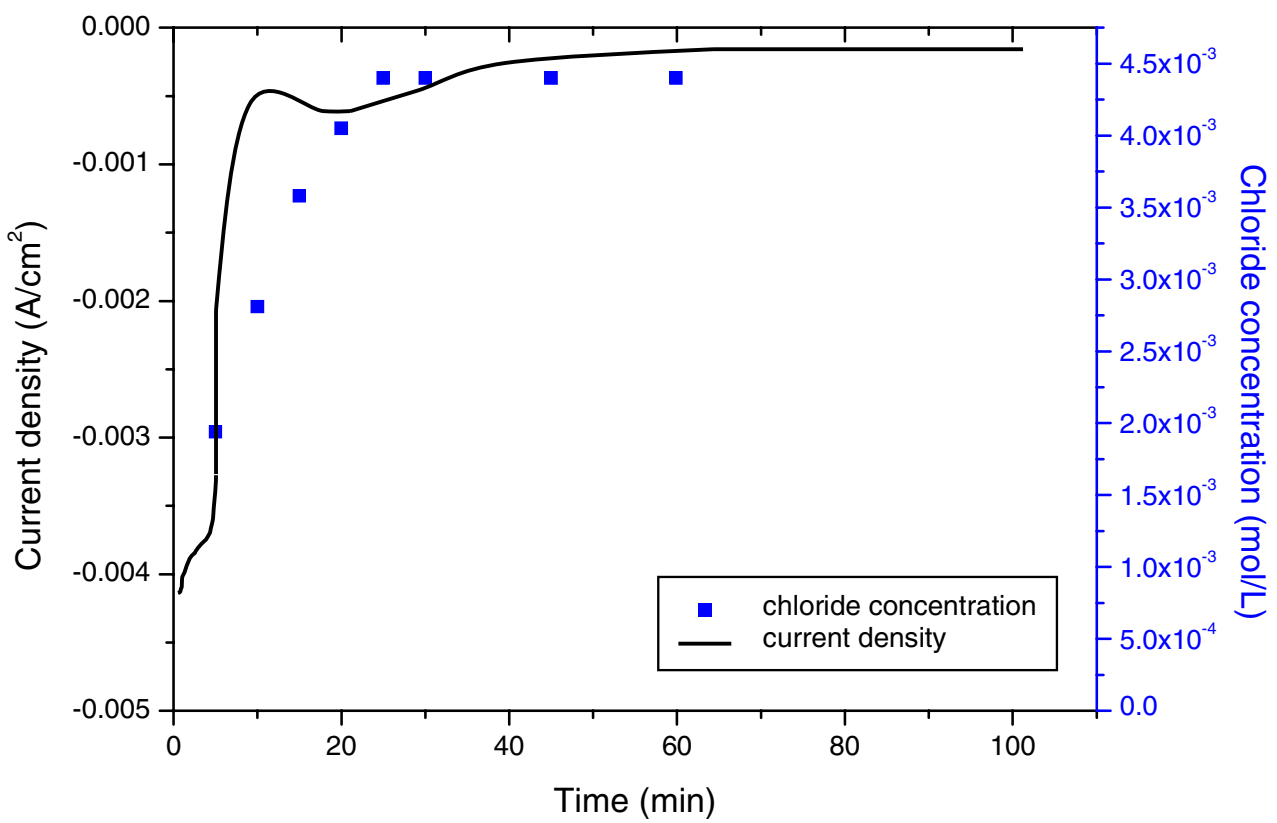


Fig. 7a-f Set of optical images of the copper/atacamite sample taken after 0 minutes (a), 5 minutes (b), 30 minutes (c), 60 minutes (d), 60 minutes with sample changed to a fresh sesquicarbonate solution (e) and 105 minutes (f) of treatment
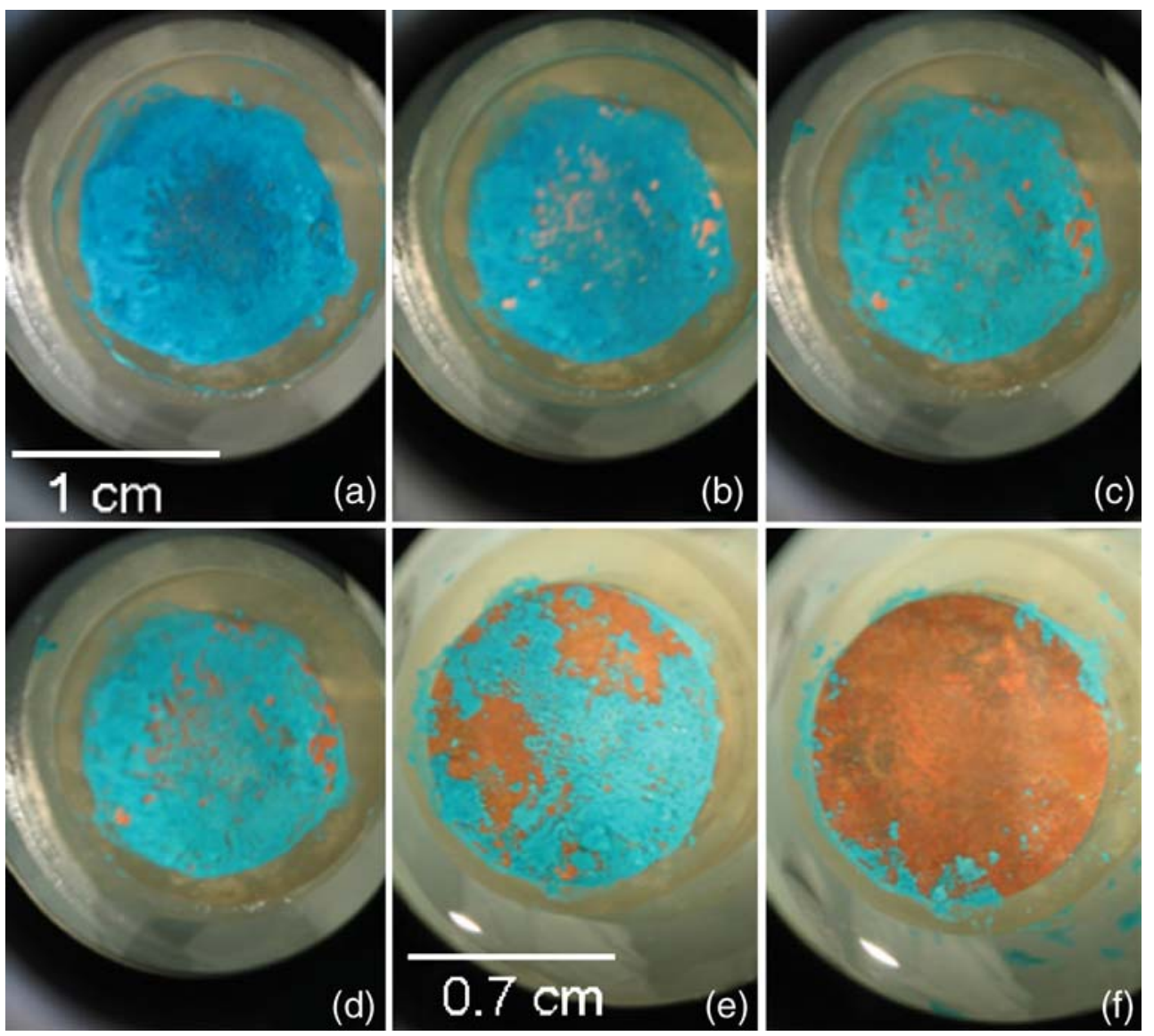

wetting is shown along the top. In each case, the sequence shows the loss of chloride and the increase in copper and cuprite. The images on the left (time $=0$ minutes) show a complex spectrum where the diffraction patterns due to atacamite and the underlying copper are clearly visible. The atacamite disappears quite rapidly and cuprite can be discerned from about $50 \mathrm{~min}$ onwards. There is a significant increase in the intensity of the two rings characteristic of copper over time, as the thickness of the overlayer reduces.

It is clear from the data above, and from visual observation, that the chloride becomes detached from the surface and dissolves rather than being converted to cuprite. The interface region converts to a cuprite layer which is much thinner than

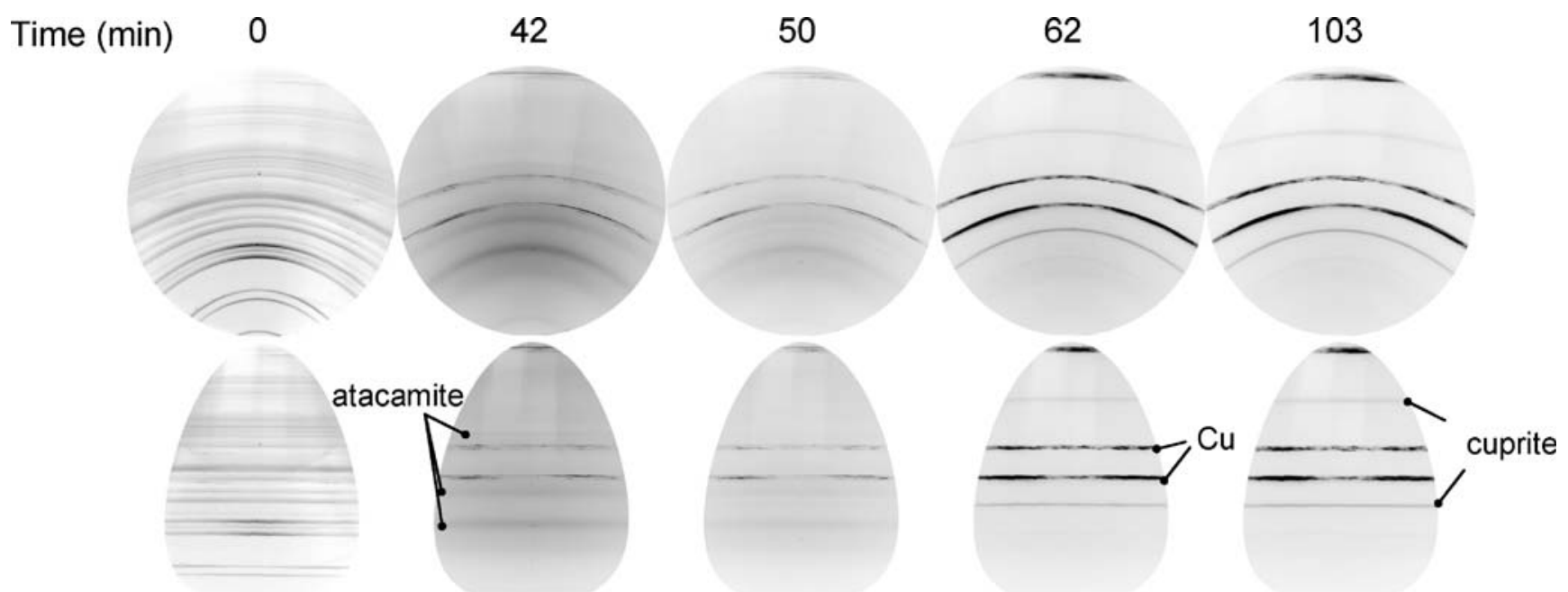

Fig. 8 Reflection SR-XRD images from the Mar CCD camera on XMaS, and the reprojected images from esaProject 
the original corrosion-hence the increase in copper signal in the diffraction patterns. There may also be some copper regrowth, although this is not yet certain.

\section{Conclusions}

A complimentary set of electrochemical, microscopic and synchrotron X-ray techniques have been used to examine the effects of electrolytic treatment with weak polarization on corroded copper artefacts, where chlorides form a substantial part of the corrosion. We show that SR-XRD images follow the removal of the chlorides and the development of a cuprite layer over time. These data, together with SEM cross-sections, show that the chloride is replaced by a much thinner cuprite layer, and that chlorine is lost to the solution. The overall effect is that the corrosion becomes detached from the surface before dissolving, and cuprite forms at the original interface.

Acknowledgements The authors gratefully acknowledge the following for their help: D. Richards and P. Van Hoe (cell construction); B. Schotte and G. Jones (help with the measurements); Drs. L. Bouchenoire, C. Degrigny, J. V. McPherson, J. Robinson, and R. F. Pettifer and Profs. E. Temmerman and P. A. Thomas (advice and discussions). The work was supported by Ghent University (BOF grant). M. G. D. thanks Cameca $\mathrm{GmbH}$ for their financial support.

\section{References}

1. Oddy WA, Hughes MJ (1970) Stud Conserv 15:183-189

2. Organ RM (1963) In: Thomson G (ed) Recent advances in conservation. Butterworths, London, p 128

3. Plenderleith HJ, Werner AEA (1971) The conservation of antiquities and works of art. Oxford University Press, Oxford

4. Hamilton DL (1998) Methods of conserving underwater archaeological material culture. Conservation Files: ANTH 605, Conservation of Cultural Resources I. Nautical Archaeology Program, Texas A\&M University, College Station, TX (see http://nautarch. tamu.edu/, last accessed 6th October 2006)

5. Leyssens K, Adriaens A, Pantos E, Degrigny C (2004) In: Ashton J, Hallam D (eds) Metal 04: Proceedings of the International Conference on Metals Conservation. National Museum of Australia, Canberra, p 332

6. Leyssens K, Adriaens A, Degrigny C (2005) In: International Council of Museums Committee for Conservation (ed) ICOM-CC 14th triennial meeting. James \& James, London, p 301

7. Leyssens K, Adriaens A, Dowsett M, Schotte B, Oloff I, Pantos E, Bell A, Thompson S (2005) Electrochem Commun 7:1265-1270

8. Leyssens K, Adriaens A, Degrigny C, Pantos E (2006) Anal Chem 78(8):2794-2801

9. Païn S, Bertholon R, Lacoudre N (1991) Stud Conserv 36:33-43

10. Bertholon R, Bell B, Blengino J-M, Lacoudre N (1997) In: MacLeod ID, Pennec S, Robbiola L (eds) Metal 95. James \& James, London, p 209

11. Lamy C (1997) Stabilisation d'objets archéologiques chlorurés en alliage cuivreux. Report ARC'Antique, Nantes, France

12. Ehanti E (2005) BROMEC 14:11

13. Dowsett M, Adriaens A (2006) Anal Chem 78:3360-3365 